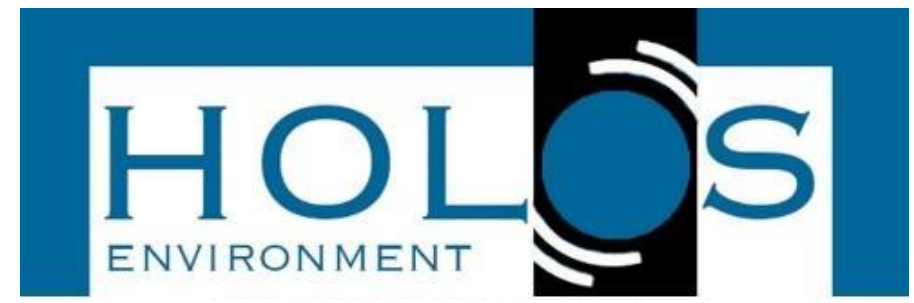

\title{
GEOTECNOLOGIAS APLICADAS NA ANÁLISE DO RISCO DE CONTAMINAÇÃO DE POÇOS DE ÁGUA NO MUNICÍPIO DE SOROCABA, SP
}

\section{GEOTECHNOLOGIES APPLIED IN THE ANALYSIS OF THE CONTAMINATION RISK OF WATER WELLS IN SOROCABA CITY SP, BRAZIL}

\author{
Liliane Moreira Nery; Vanessa Cezar Simonetti²; Levi Pompermayer Machado; \\ Darllan Collins da Cunha e Silva ${ }^{3}$
}

Artigo recebido em: 10/02/2020 e aceito para publicação em: 19/02/2020.

DOI: http://dx.doi.org/10.14295/holos.v20i2.12376

\begin{abstract}
Resumo: Em decorrência do crescimento da cidade de Sorocaba e da quantidade de empresas que se instalam todos os anos no município, o presente estudo teve como objetivo avaliar os riscos de contaminação dos poços de água próximos a áreas contaminadas utilizando técnicas de geoprocessamento. Para o levantamento das áreas contaminadas foi utilizado o inventário disponibilizado pela Companhia Ambiental do Estado de São Paulo (CETESB), e a localização dos poços outorgados do município foram obtidos através da base de dados do Departamento de Águas e Energia Elétrica (DAEE). A concentração de áreas contaminadas foi avaliada por meio do estimador de densidade de Kernel, e os valores foram ordenados em três diferentes classes de riscos de contaminação, sendo baixo, médio e alto. Os resultados demonstraram que $17,3 \%$ das áreas contaminadas estão inseridas na zona de alto risco, enquanto as zonas de risco médio obtiveram $50,0 \%$ dos pontos de contaminação. As zonas de alto e médio risco contemplam 57 poços de água, apresentando riscos de contaminação eminentes, podendo comprometer a saúde humana a partir do consumo e uso da água destes poços. A utilização de ferramentas de geoprocessamento na análise de riscos de contaminação mostrou-se eficaz, permitindo a seleção de zonas prioritárias para a gestão e monitoramento de poços de água.
\end{abstract}

Palavras-chave: Água subterrânea. Geoprocessamento. Riscos ambientais. Densidade de Kernel.

Abstract: Due to the growth of the Sorocaba city and the amount of companies that install themselves in the municipality every year, this study aimed to assess the risks of contamination of water wells near contaminated areas using geoprocessing techniques. To survey the contaminated areas was used the inventory provided by the Environmental Company of the State of Sao Paulo (CETESB) and the location of water wells in the municipality were obtained from the database of the Department of Water and Electrical Energy (DAEE). The concentration of contaminated sites was assessed by kernel density estimator, and the values were ordered in three different classes of contamination risks, being low, medium and high. The results demonstrated that $17.3 \%$ of the contaminated areas are located in the high risk zone, while the medium risk zones covered $50.0 \%$ of the contamination points. The high and medium risk zones include 57 water wells with eminent contamination risks, which can compromise human health from the consumption and use of water from the

\footnotetext{
${ }^{1}$ Universidade de Sorocaba (Uniso), Sorocaba, SP. E-mail: (lilianemoreiranery@gmail.com)

2 Universidade Estadual Paulista "Júlio de Mesquita Filho" (UNESP), Campus de Sorocaba, Brasil. E-mail: (vanessa.simonetti@prof.uniso.br)

3 Universidade Estadual Paulista "Júlio de Mesquita Filho" (UNESP), Campus de Registro, Brasil. E-mails: (levi.p.machado@unesp.br, darllan.collins@unesp.br)
} 
wells present in these zones. The use of geoprocessing tools in the analysis of risks of contamination proved to be effective, allowing the selection of priority zones for the management and monitoring of water wells.

Keywords: Groundwater. Geoprocessing. Environmental risks. Kernel density.

\section{INTRODUÇÃO}

O meio ambiente vem sofrendo com a ação antrópica desde que o ser humano começou a desenvolver as suas atividades produtivas, concomitante aos processos industrias de transformação, extração, estocagem, manuseio de matérias-primas e produtos, transportes, entre outras atividades, passou a ser receptor de todos os resíduos e substâncias químicas advindos do processo de industrialização. Destas ações surgiram as áreas contaminadas e inúmeros impactos negativos sobre a saúde e o meio ambiente (MORAES; ECHEVENGUÁ TEIXEIRA; MAXIMIANO, 2013; SILVA; MESQUITA, 2018).

As áreas contaminadas oferecem riscos à saúde da população, uma vez que comprometem a qualidade das águas subterrâneas, do ar, do solo e dos compartimentos ambientais em diferentes níveis (DI GIULIO et al., 2012).

Estudos demonstram a necessidade da realização de inventários de áreas contaminadas indicando que as atividades humanas interferem negativamente na saúde do planeta, sendo assim, o homem passa a ter um novo olhar quanto à qualidade ambiental do meio onde vive, desenvolvendo ações e estratégias de preservação do meio ambiente (LIMA et al., 2017; MORAES; ECHEVENGUÁ TEIXEIRA; MAXIMIANO, 2013).

A Lei Estadual Paulista n. -13.577 de 08 de julho de 2009, define como área contaminada o terreno, local, instalação, edificação ou benfeitoria que contenha quantidades ou concentrações de matéria em condições que causem ou possam causar danos à saúde humana, ao meio ambiente ou a outro bem a proteger (SÃO PAULO, 2009), sendo que a Resolução CONAMA 420/09 estabelece os critérios para a definição de valores orientadores para prevenção de contaminações e de diretrizes para o gerenciamento de áreas contaminadas para evitar e prevenir alterações prejudiciais num determinado meio, que possa resultar na sua perda de funcionalidade, além de danos ao equilíbrio ecológico do local podendo danificar os seres vivos como um todo (CONAMA, 2009).

Lima et al. (2017) relata a importância da realização de inventários de áreas contaminadas para que as medidas adequadas relacionadas ao gerenciamento de áreas contaminadas (GAC) possam ser realizadas. Já Habermann e Gouveia (2014) expõem a 
importância do GAC para evitar que imóveis degradados sejam reincorporados a malha urbana de forma inadequada e precipitada, sem qualquer preocupação quanto aos riscos de contaminação. Araújo-Moura e Caffaro Filho (2015), destacam que as regiões Sul e Sudeste avançaram consideravelmente no gerenciamento de áreas contaminadas quando comparados as demais regiões do Brasil.

Visto o crescimento da cidade de Sorocaba e a quantidade de empresas que se instalam todos os anos, é de suma importância o levantamento de dados sobre as áreas contaminadas existentes na região. Nesse sentido, o uso de Sistemas de Informação Geográfica (SIG) e ferramentas de geoprocessamento são importantes aliadas na análise e inferência de áreas contaminadas (PESSOA et al., 2003; LOURENÇO; LANDIM, 2005; OLIVEIRA et al., 2008; LOURENÇO et al., 2015).

A utilização de ferramentas de geoprocessamento tem se mostrado eficaz para o desenvolvimento de estudos relacionados a delimitação e identificação de áreas contaminadas (BREMER BREMER et al., 2016; VALLADARES et al., 2009) e para identificação de atividades potencialmente contaminantes, correlacionando essas áreas com a vulnerabilidade natural de águas subterrâneas (MARION, 2012).

Diante do exposto, o objetivo desse trabalho consistiu na análise da distribuição espacial das áreas contaminadas e na elaboração de uma metodologia para a classificação dos riscos associados à contaminação dos poços de água.

\section{MATERIAL E MÉTODOS}

\section{1 Área de Estudo}

Com aproximadamente 671.186 habitantes a cidade de Sorocaba está localizada a sudeste do Estado de São Paulo, a cem quilômetros da capital e está inserida na macrometrópole de São Paulo, região caracterizada devido ao grande aglomerado urbano (NERY et al., 2019) (Figura 1). 
Figura 1 - Localização da área de estudo

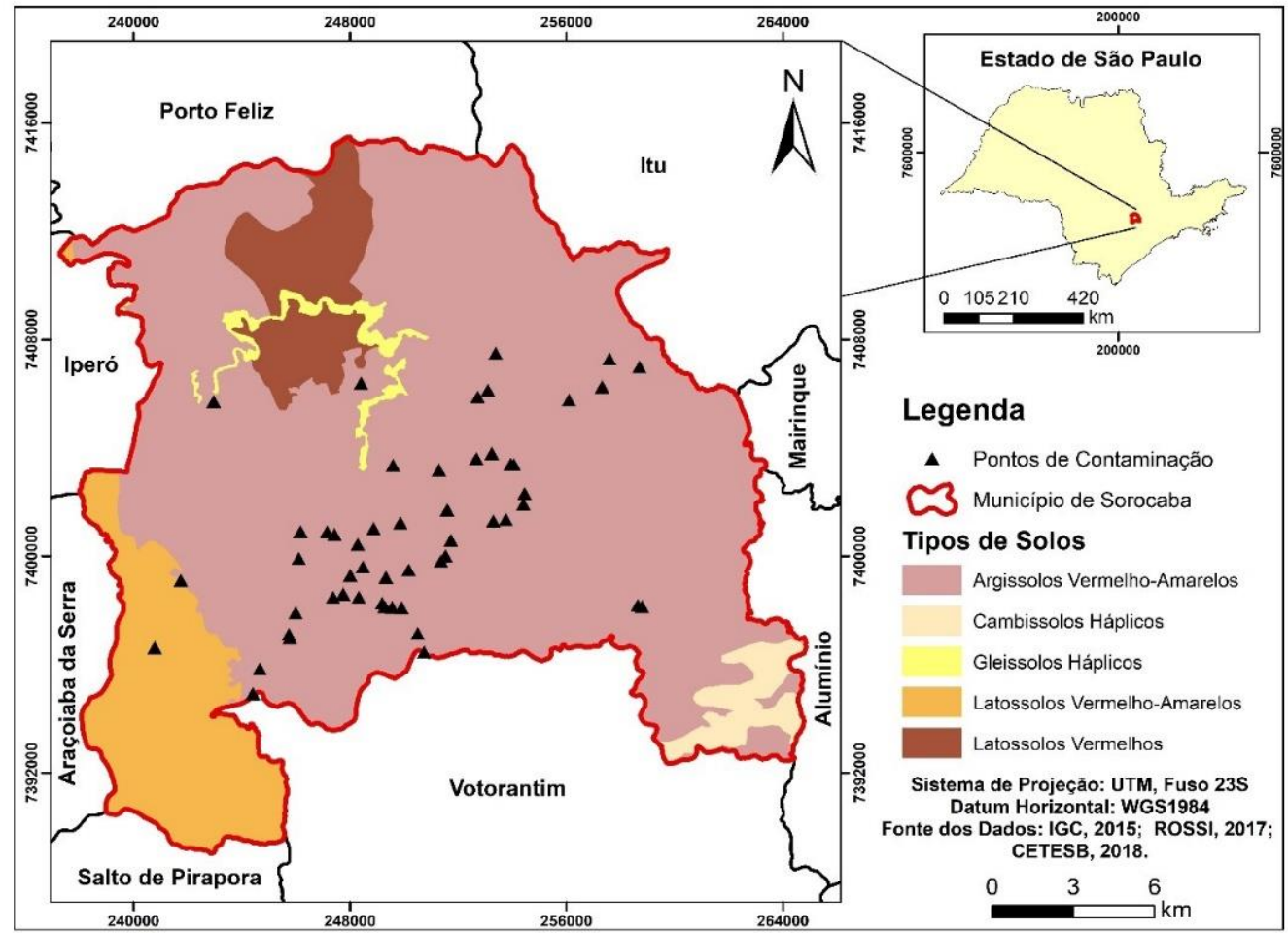

Fonte: Elaborado pelos autores

O clima do município encontra-se na zona subtropical úmida (Cfa), segundo a classificação Köppen-Geiger, possuindo verões quentes, abafados e frequentes trovoadas, com inverno moderado não muito seco e temperatura média em torno de $19,4^{\circ} \mathrm{C}$ (LOURENÇO; SILVA; SALES, 2014; SIMONETTI et al., 2018).

Sua cobertura vegetal predominante corresponde ao bioma da Mata Atlântica, com traços de Cerrado, possuindo uma matriz composta por Floresta Estacional Semidecidual., Floresta Ombrófila Mista, Floresta Ombrófila Densa e Cerrado sensu lato (LOURENÇO; SILVA; SALES, 2014; LOURENÇO et al., 2015; OLIVEIRA et al., 2016; SIMONETTI et al., 2019).

\subsection{Levantamento de áreas contaminadas e poços outorgados}

A metodologia de gerenciamento de áreas contaminadas no Estado de São Paulo é estipulada pela Decisão de Diretoria CETESB n.ำ 038 de 07 de fevereiro de 2017, que dispõe sobre a aprovação do Procedimento para a Proteção da Qualidade do Solo e das Águas Subterrâneas, e estabelece Diretrizes para Gerenciamento de Áreas Contaminadas no Âmbito do Licenciamento Ambiental em função da publicação da Lei Estadual no 
13.577/2009 e seu Regulamento, aprovado por meio do Decreto n.ำ59.263/2013 (CETESB, 2017; SÃO PAULO, 2009).

Deste modo, o levantamento das áreas contaminadas da cidade de Sorocaba foi realizado através do inventário de áreas contaminadas disponibilizadas pela Agência Ambiental do Estado de São Paulo (CETESB, 2018).

As áreas contaminadas foram classificadas de acordo com o artigo $3^{\circ}$ e $8^{\circ}$ do Decreto Estadual n. .59 .263 de 05 de julho de 2013 (SÃO PAULO, 2013), conforme demonstrado na Tabela 1.

Tabela 1 - Classificação das áreas contaminadas de acordo com Decreto Estadual 59.263/2013 Classificação Descrição

\begin{tabular}{|c|c|}
\hline $\begin{array}{l}\text { Área Contaminada sob } \\
\text { Investigação }(\mathrm{ACl})\end{array}$ & $\begin{array}{l}\text { Área onde foram constatadas por meio de investigação confirmatória } \\
\text { concentrações de contaminantes que colocam, ou podem colocar, em risco } \\
\text { os bens a proteger }\end{array}$ \\
\hline Área Contaminada em & \\
\hline $\begin{array}{c}\text { Processo de } \\
\text { Remediação (ACRe) }\end{array}$ & Área onde estão sendo aplicadas medidas de remediação \\
\hline $\begin{array}{l}\text { Área Contaminada em } \\
\text { Processo de } \\
\text { Reutilização (ACRu) }\end{array}$ & $\begin{array}{l}\text { Área contaminada onde se pretende estabelecer um uso do solo diferente } \\
\text { daquele que originou a contaminação }\end{array}$ \\
\hline $\begin{array}{l}\text { Área Contaminada com } \\
\text { Risco Confirmado } \\
\text { (ACRi) }\end{array}$ & $\begin{array}{l}\text { Área onde foi constatada, por meio de investigação detalhada e avaliação } \\
\text { de risco, contaminação no solo ou em águas subterrâneas, a existência de } \\
\text { risco à saúde ou à vida humana, ecológico. }\end{array}$ \\
\hline $\begin{array}{l}\text { Área com Potencial de } \\
\text { Contaminação (AP) }\end{array}$ & $\begin{array}{l}\text { Área onde são ou foram desenvolvidas atividades que, por suas } \\
\text { características, possam acumular quantidades ou concentrações de } \\
\text { matéria em condições que a tornem contaminada }\end{array}$ \\
\hline $\begin{array}{l}\text { Área em Processo de } \\
\text { Monitoramento para } \\
\text { Encerramento (AME) }\end{array}$ & $\begin{array}{l}\text { Área na qual não foi constatado risco ou as metas de remediação foram } \\
\text { atingidas após implantadas as medidas de remediação, encontrando-se } \\
\text { em processo de monitoramento para verificação da manutenção das } \\
\text { concentrações em níveis aceitáveis }\end{array}$ \\
\hline & Área anteriormente contaminada que, depois de submetida às medidas de \\
\hline $\begin{array}{l}\text { Área Reabilitada para o } \\
\text { Uso Declarado (AR) }\end{array}$ & $\begin{array}{l}\text { intervenção, ainda que não tenha sido totalmente eliminada a massa de } \\
\text { contaminação, tem restabelecido o nível de risco aceitável à saúde } \\
\text { humana, ao meio ambiente e a outros bens a proteger }\end{array}$ \\
\hline $\begin{array}{l}\text { Área Suspeita de } \\
\text { Contaminação (AS) }\end{array}$ & $\begin{array}{l}\text { Área com indícios de ser uma Área contaminada conforme resultado da } \\
\text { avaliação preliminar }\end{array}$ \\
\hline
\end{tabular}

Fonte: São Paulo (Estado), 2013

Holos Environment (2020), 20 (2): 214-230. 218 
As coordenadas geográficas dos 52 pontos de contaminação do ano de 2018 , bem como os 433 poços de água outorgados pelo Departamento de Águas e Energia Elétrica (DAEE) foram exportados para o software ArcGis 10.5 (Figura 2).

Figura 2 - Pontos de áreas contaminadas e poços outorgados

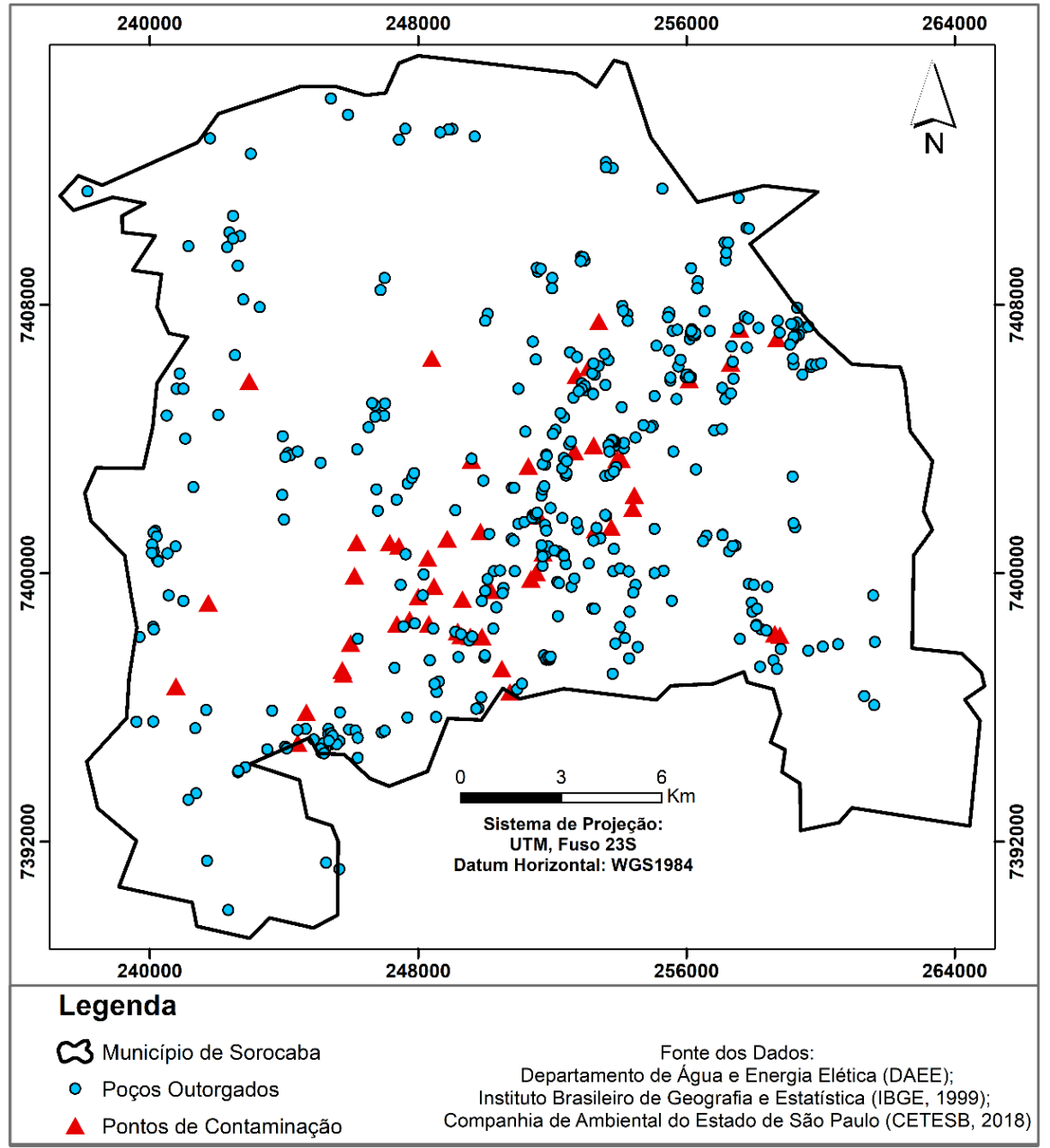

Fonte: Elaborado pelos autores

Com base nas informações da Figura 2 foram gerados mapas de distribuição espacial dos tipos de empreendimentos com áreas contaminadas no município; classificação das áreas contaminadas e mapa das zonas de risco com a presença de poços de água. 


\subsection{Uso do estimador de densidade de Kernel na inferência dos riscos das áreas contaminadas}

Para avaliar a concentração de áreas contaminadas no município foi utilizado o estimador de densidade de Kernel, que trata de método não paramétrico com um estimador que delineia uma vizinhança de modo esférica na imediação de cada ponto da amostra, que corresponderá ao raio de influência. Assim, o valor estimado para o pixel será a soma dos valores kernel justapostos, sendo então divididos pela área de cada raio de pesquisa (SILVERMAN, 1986; MAIOR; CÂNDIDO, 2014). De acordo com Weber e Wollmann (2016), o método kernel é muito empregado no mapeamento e estimativa de distribuições espaciais de pontos.

Assim, foram inseridos os pontos de contaminação com as respectivas coordenadas no software ArcGis 10.5 e, a partir da ferramenta Spatial Analyst Tools, foi aplicado o algoritmo estatístico Kernel Density, para estabelecer uma função de núcleo de densidade de modo a ajustar uma superfície suavizada.

Em posse dos pontos representando cada área contaminada, o algoritmo foi aplicado retornando um valor que foi ajustado de acordo com sua amplitude em três classes de riscos de contaminação, sendo baixo para o risco compreendido entre 0 e 0,5, representando a classe de menor amplitude; médio para a classe de 0,51 a 1,0 e alto para a faixa acima de 1,01. Para melhor representação visual, foi atribuída cor branca para o risco baixo; laranja para o risco médio e vermelho para o risco alto, com $50 \%$ de transparência respectivamente, com o intuito de evidenciar a sobreposição dos pontos no município, sendo gerada a superfície de riscos.

A partir do estabelecimento dos riscos, foram então inseridas às coordenadas dos poços de água, sendo possível identificar os poços de água presentes em cada respectivo risco. Ainda, a superfície com as zonas de risco serviu de suporte às outras inferências, como na identificação dos contaminantes; classificação e tipos de empreendimentos presentes em cada zona.

\section{RESULTADOS E DISCUSSÃO}

Diante da necessidade do conhecimento dos impactos provocados pelas áreas contaminadas, bem como a necessidade de estudos que demonstrem a sua distribuição 
espacial no sentido de deliberar ações de monitoramento de forma pontual, a Figura 3 ilustra as áreas contaminadas, assim como os respectivos contaminantes do município de Sorocaba de acordo com as zonas de risco identificadas.

Figura 3 - Identificação das zonas de riscos

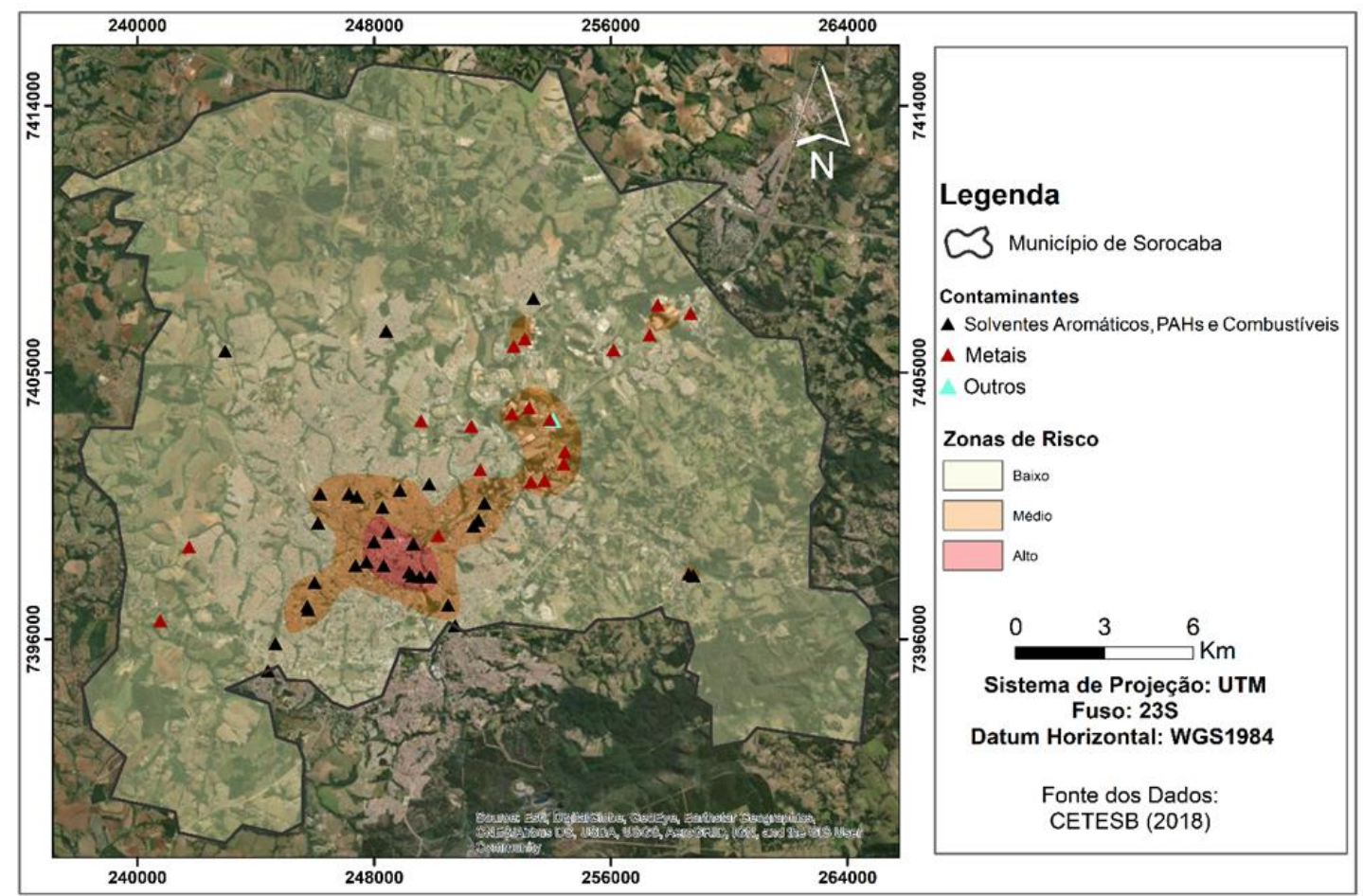

Fonte: Elaborado pelos autores

A partir da Figura 3 foi possível inferir que 17,3\% das áreas contaminadas estão inseridas na zona de alto risco, enquanto as zonas de risco médio contemplaram 50,0\% dos pontos de contaminação. Já as zonas de baixo risco tiveram 32,7\%.

Dos contaminantes inseridos nas zonas de risco médio, 57,7\% consistiram em solventes, PAHs e combustíveis, enquanto os metais e outros inorgânicos representaram $38,5 \%$ nas zonas avaliadas, sendo que 3,8\% envolveram outros tipos de contaminantes, de acordo com a classificação da CETESB (2018).

Dentre os contaminantes nas zonas de risco médio também há uma prevalência dos solventes, PAHs e combustíveis, representando $57,7 \%$. No entanto, $38,5 \%$ correspondem aos metais e apenas 3,8\% ( 3 áreas contaminadas) tratam-se de contaminações por anilinas, ftalatos e TPH (hidrocarbonetos totais de petróleo).

Em relação aos postos de combustíveis, os contaminantes presentes em sua maioria são solventes aromáticos, e compostos formados por benzeno, tolueno, etilbenzeno e 
xilenos (BTEX). Esses compostos, que estão presentes no diesel e na gasolina, possuem grande relevância ambiental devido ao efeito toxicológico que podem causar, visto que os contaminantes compostos por benzeno e etilbenzeno são cancerígenos (SANTOS et al., 2018).

No Estado de São Paulo, a CETESB em 2002, divulgou a primeira versão do cadastro de áreas contaminadas, reconhecendo publicamente a existência de 255 áreas contaminadas no Estado (MORAES; ECHEVENGUÁ TEIXEIRA; MAXIMIANO, 2013), sendo 2 delas na cidade de Sorocaba. A última atualização, ocorrida em dezembro de 2018, registrou 52 áreas contaminadas na cidade, num total de 6.110 áreas contaminadas no Estado. Segundo dados do IBGE (2019), de 2007 a 2017 mais de 37.000 novas indústrias de transformação surgiram no Brasil, portanto, sugere-se que tamanho crescimento industrial está relacionado com o aumento no número de áreas contaminadas. Os tipos de empreendimentos foram analisados espacialmente e ilustrados na Figura 4.

Figura 4 - Tipos de empreendimentos com áreas contaminadas no município de Sorocaba

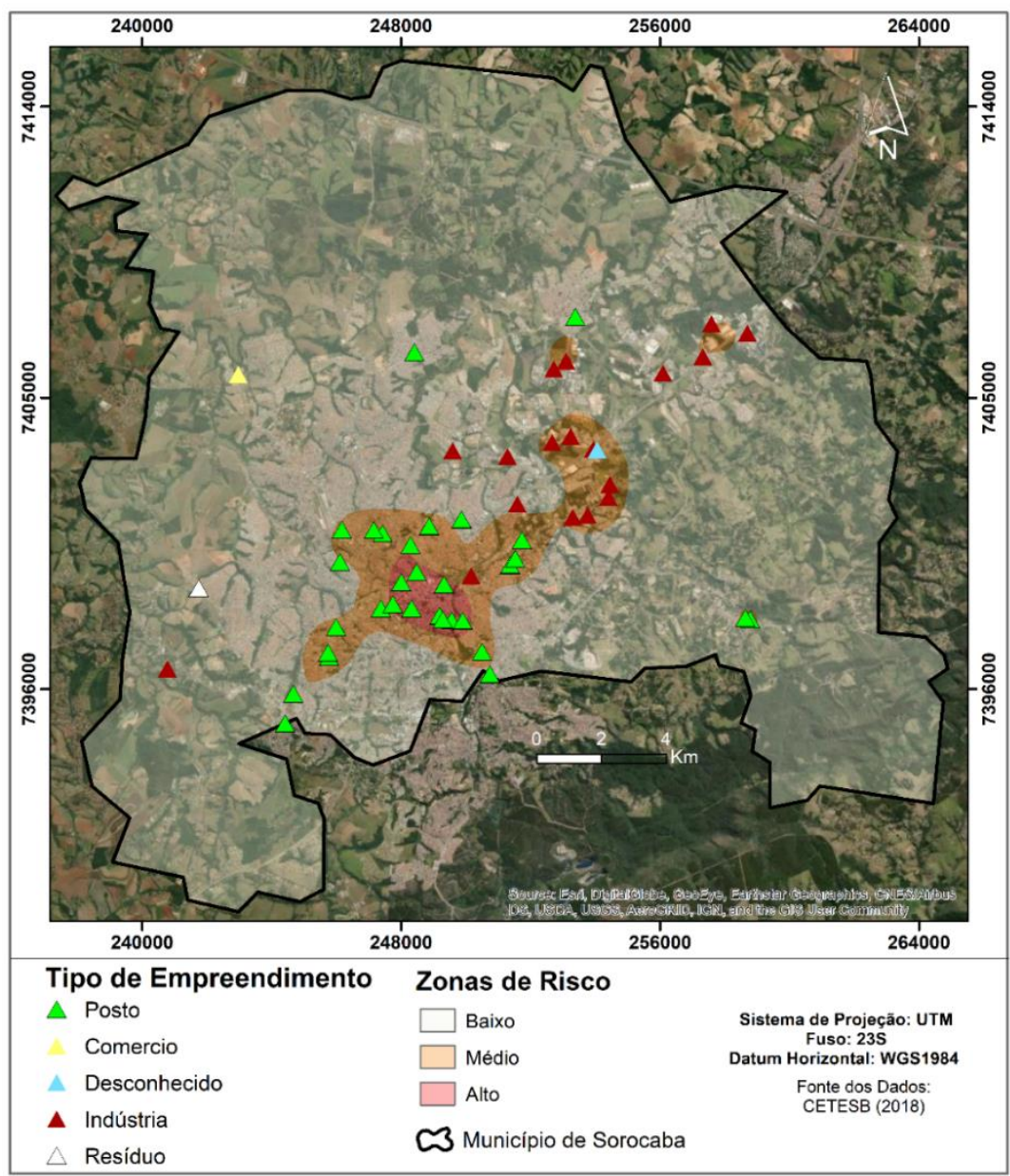

Fonte: Elaborado pelos autores 
A partir da Figura 4, foi possível inferir que o tipo de empreendimento mais presente no município são os postos de combustíveis, totalizando 59\%. Nas zonas de risco médio e alto, foram contabilizados 22 postos, ou seja, do montante de postos de combustíveis inventariados pela CETESB, $42,3 \%$ estão em zonas de risco presentes predominantemente em zonas altamente urbanizadas. De modo geral, os vazamentos em postos de combustíveis ocorrem devido as irregularidades na infraestrutura, manutenção e desgastes dos tanques de armazenamento de combustíveis, que muitas vezes se encontram em estado avançado de oxidação (MENEZES, 2011), comprometendo a integridades dos mesmos.

Os pontos de contaminação por industrias se concentram, de acordo com o Plano Diretor de Sorocaba, na Zona Industrial do município (SOROCABA, 2014); porém, a proximidade da Zona Industrial com demais Zonas Residências em seu entorno reforça a premissa de que o crescimento desordenado do número de indústrias está relacionado ao aumento de pontos de contaminação, resultando em situações de risco à saúde da população exposta aos contaminantes. O mapeamento de perigo de contaminação na região de Indaiatuba a Capivari realizado por Iritani et al. (2017), conclui que o maior perigo de contaminação está associado aos distritos industriais.

As causas das contaminações são variadas, com problemas em diferentes níveis, desde a armazenagem e infiltrações de substâncias, descarte disposição de resíduos, até emissões atmosféricas. Quanto ao restante dos segmentos, as fontes de contaminação incluem armazenamento, descarte disposição e, também, fontes desconhecidas.

A classificação das áreas contaminadas do município é demostrada na Figura 5.

De acordo com a Figura 4, a distribuição espacial das áreas contaminadas no município de Sorocaba de acordo com a zona de alto risco revelou que 66,7\% das áreas contaminadas nas zonas de alto risco estão em processo de remediação, enquanto $22,2 \%$ estão em processo de investigação e $11,1 \%$ encontra-se em processo de monitoramento para encerramento.

Com relação as 25 áreas presentes nas zonas de risco médio, 68,0\% estão contaminadas, sendo $28,0 \%$ sob investigação, $12 \%$ estão contaminadas com risco confirmado e $28,0 \%$ estão em processo de remediação. Ainda nas classes de risco médio, $16,0 \%$ estão reabilitadas para o uso, $12,0 \%$ estão em processo de monitoramento para encerramento e 4,0\% estão contaminadas em processo de reutilização. 
Figura 5 - Classificação das áreas contaminadas do município de Sorocaba

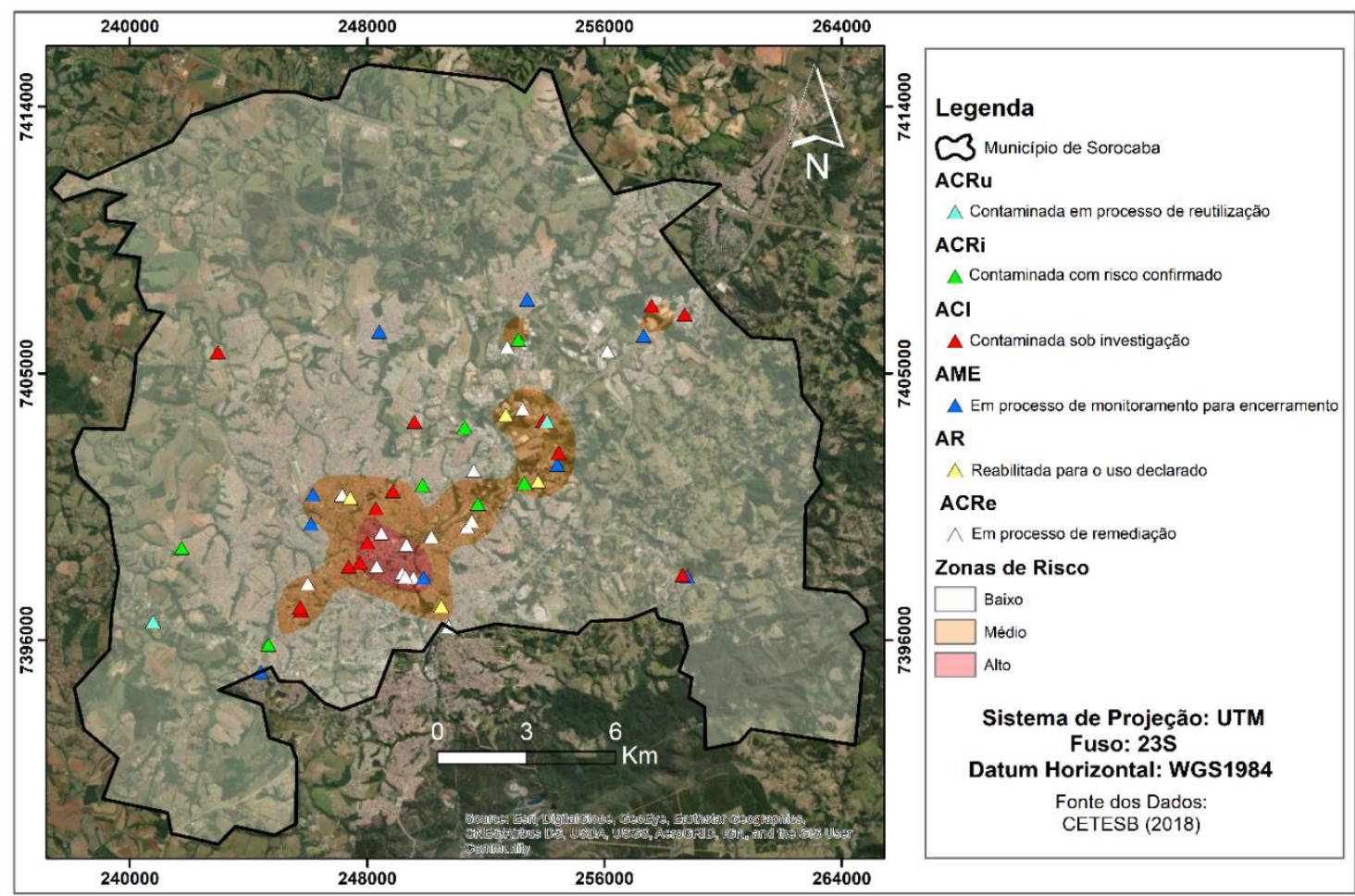

Fonte: Elaborado pelos autores

Brito e Vasconcelos (2012) também observaram em estudos referente aos processos de licenciamento ambiental de postos de combustíveis em Minas Gerais, um baixo índice de áreas contaminadas reabilitadas, apenas $2 \%$, e verificou-se que $38 \%$ das áreas eram classificadas como Áreas Contaminadas sob Intervenção e 31\% classificadas como Áreas Contaminadas sob Investigação.

Após a inferência das zonas de riscos foi realizado um recorte do estudo somente nas zonas que apresentaram riscos médio e alto, com vistas a retratar de forma pormenorizada os principais poços de água presentes nessas áreas (Figura 6).

Foi possível verificar, a partir da Figura 4, que a zona de alto risco de contaminação está inserida predominantemente em área urbana, contemplando nove poços de água. Quanto aos contaminantes presentes nessa zona de alto risco, 100\% são compostos por solventes aromáticos, PAHs e combustíveis automotivos.

O aumento no interesse de se realizar o levantamento das áreas contaminadas por combustíveis, surgem em decorrência da complexidade, toxicidade e mobilidade no ambiente dos compostos do grupo BTEX presentes nos combustíveis (LIMA et al., 2017).

Entre os riscos existentes à saúde humana devido à exposição a esses contaminantes, destaca-se os riscos genotóxicos e hematóxicos causados pelo benzeno, 
que pode ser apontado como o agente mais preocupante no tocante à saúde pública (COSTA; GOLDBAUM, 2017; ANDRADE; AUGUSTO; JARDIM, 2010).

Figura 6 - Zonas de risco com presença de poços de água

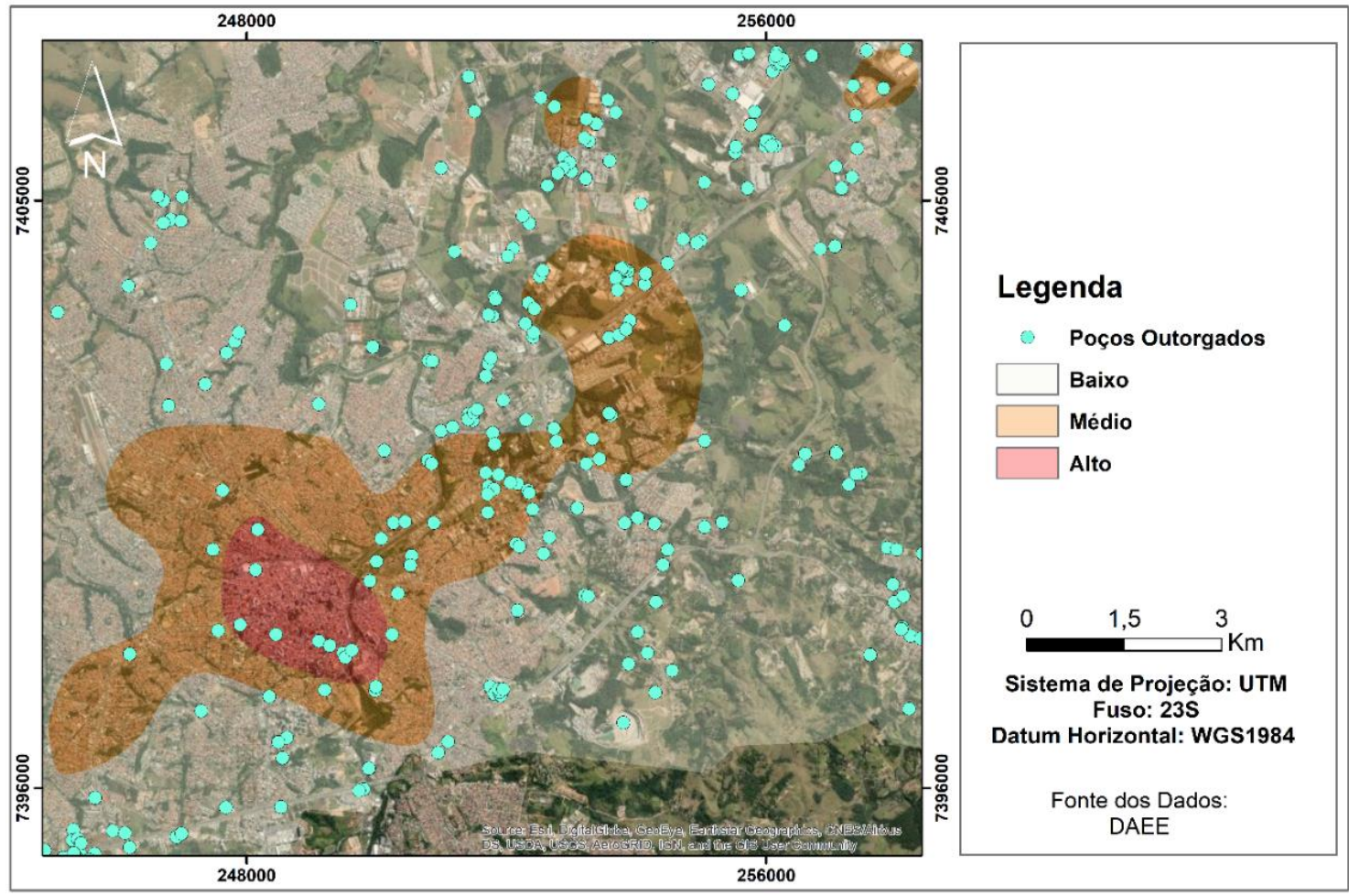

Fonte: Elaborado pelos autores

A hematoxicidade do benzeno se manifesta pela diminuição de células sanguíneas gerando agravos como anemia, leucopenia, plaquetopenia, ou o conjunto dessas três complicações, sendo que esse contaminante também causa alterações cromossomiais que são consideradas a explicação mais provável para sua carcinogenicidade (COSTA; GOLDBAUM, 2017).

As preocupações referentes à poluição química dos ecossistemas ambientais adquirem maior visibilidade pública a partir das últimas décadas do século XX (ARAÚJO; GÜNTHER, 2009), sendo que as áreas contaminadas têm sido uma constante preocupação para os gestores públicos (LIMA et al., 2017).

As zonas de risco médio contemplaram 48 poços de água, nesse sentido, 57 poços de água apresentam riscos de contaminação eminentes, devendo receber atenção dos órgãos fiscalizadores. O problema se agrava diante do quadro dos meios impactados, uma vez que $88,5 \%$ das áreas contaminadas do município possuem como meio físico à água 
subterrânea, podendo comprometer a saúde humana a partir do consumo e uso da água dos poços presentes nessas zonas.

O estudo demonstrou que $13,2 \%$ dos poços de água outorgados pelo DAEE no município estão com elevados riscos de contaminação condicionados ao tipo de contaminante e ao meio impactado, visto que o lençol freático representa o meio mais impactado analisado.

Diante dos riscos apresentados à saúde pública em decorrência dos tipos de poluentes identificados nas áreas contaminadas com riscos classificados em médio e alto, assim como a quantidade de poços localizados nesses locais e a elevada densidade demográfica dessas zonas, são visíveis a vulnerabilidade e a suscetibilidade da população ao contato com os contaminantes identificados, sendo de grande importância a atuação de gestores públicos para o acompanhamento, monitoramento e fiscalização da remediação das áreas contaminadas inventariadas pela CETESB, bem como o controle sobre o consumo de água subterrânea próximas a esses locais e a concessão de novas outorgas.

A gestão de controle de poluição e gerenciamento de áreas contaminadas deve ser compartilhada pelos órgãos públicos e empresas privadas, de modo que estes atuem de forma preventiva no controle e monitoramento de atividades potencialmente poluidoras, evitando assim, que os números de áreas contaminadas aumentem gradativamente como observado nos últimos anos, gerando agravos à saúde pública e danos irreversíveis ao meio ambiente.

\section{CONCLUSÕES}

A análise dos riscos de contaminação de poços de água por meio de técnicas de geoprocessamento favorece a análise devido a espacialidade dos dados, evidenciando as zonas prioritárias para o monitoramento de poços de água com elevado risco de contaminação.

Assim, foi possível inferir que $59 \%$ das áreas contaminadas no município são provenientes de postos de combustíveis, e o meio mais impactado são as águas subterrâneas. As contaminações derivadas de postos de combustíveis e as grandes concentrações populacionais nas imediações dessas áreas aumentam as preocupações relacionadas às questões de saúde pública e, por esta razão, estudos que objetivem a 
análise espacial de áreas contaminadas e os riscos associados principalmente ao que tange à ingestão da água de poços em zonas de riscos são de extrema importância.

Todavia, a metodologia proposta neste estudo pode servir de subsídios para a implementação de políticas públicas voltadas ao monitoramento dos poços com riscos iminentes, proporcionando o desenvolvimento de ações pontuais e emergenciais.

\section{REFERÊNCIAS}

ANDRADE, J. A.; AUGUSTO, F.; JARDIM I. C. S. F. Biorremediação de solos contaminados por petróleo e seus derivados. Eclética Química, São Paulo, v. 35, n. 3, p. 17-43, 2010.

http://dx.doi.org/10.26850/1678-4618eqj.v35.3.2010.p17-43

ARAÚJO, J. M.; GUNTHER, W. M. R. Riscos à saúde em áreas contaminadas: contribuições da teoria social. Saude soc., São Paulo, v. 18, n. 2, p. 312-324, jun. 2009.

http://dx.doi.org/10.1590/S0104-12902009000200014

ARAÚJO-MOURA, A. A. C.; CAFFARO FILHO R. A. Panorama do gerenciamento de áreas contaminadas no Brasil após a resolução CONAMA 420/09. Águas Subterrâneas, v. 29, n. 2, p. 202-212, 2015. https://doi.org/10.14295/ras.v29i2.27972

BREMER BREMER, M.H.; LOZANO GARCÍA, D. F.; RODRÍGUEZ GARCÍA M.; HORI OCHOA M. C. Caracterización de niveles de contaminación en una planta extractora de azufre utilizando imágenes de satélite de alta resolución para optimizar el plan de muestreo. Rev. Int. Contam. Ambie., México, v. 32, n. 2, p. 165-176, 2016. http://dx.doi.org/10.20937/RICA.2016.32.02.03

BRITO, G. C. B; VASCONCELOS F. C. W. A gestão de áreas contaminadas em Minas Gerais: o licenciamento como instrumento preventivo. Revista de Gestão Social e Ambiental - RGSA, São Paulo, v. 6, n. 2, p. 19-32, maio/ago. 2012. https://doi.org/10.24857/rgsa.v6i2.429

CETESB - Companhia Ambiental do Estado de São Paulo. Decisão de Diretoria no 038/2017/C, de 07 de fevereiro de 2017. Dispõe sobre a aprovação do "Procedimento para a Proteção da Qualidade do Solo e das Águas Subterrâneas", da revisão do "Procedimento para o Gerenciamento de Áreas Contaminadas" e estabelece "Diretrizes para Gerenciamento de Áreas Contaminadas no Âmbito do Licenciamento Ambiental". Disponível em:

https://cetesb.sp.gov.br/wp-content/uploads/2014/12/DD-038-2017-C.pdf. Acesso em: 30 de abr. de 2019.

CETESB - Companhia Ambiental do Estado de São Paulo. Relação de áreas contaminadas cadastradas no Estado de São Paulo (2018). Disponível em: https://cetesb.sp.gov.br/areascontaminadas/relacao-de-areas-contaminadas/. Acesso em: 30 de abr. de 2019.

CONAMA - Conselho Nacional de Meio Ambiente. Resolução no 420, de 28 de dezembro de 2009. Dispõe sobre critérios e valores orientadores de qualidade do solo quanto à presença de substâncias químicas e estabelece diretrizes para o gerenciamento ambiental de áreas contaminadas por essas substâncias em decorrência de atividades antrópicas. Diário Oficial da União, Brasília, no 249, 30 dez. 2009. p. 81-84. 
COSTA, D. F.; GOLDBAUM, M. Contaminação química, precarização, adoecimento e morte no trabalho: benzeno no Brasil. Ciênc. saúde coletiva, Rio de Janeiro, v. 22 n. 8, p. 2681-2692, ago. 2017. http://dx.doi.org/10.1590/1413-81232017228.31042016

DI GIULIO, G. M.; FIGUEIREDO, B. R.; FERREIRA, L.C.; DOS ANJOS, J. A. S. A. Experiências brasileiras e o debate sobre comunicação e governança do risco em áreas contaminadas por chumbo. Ciênc. saúde coletiva, Rio de Janeiro, vol. 17 n. 2, p. 337-349, fev. 2012. http://dx.doi.org/10.1590/S1413-81232012000200008

HABERMANN, M.; GOUVEIA, N. Requalificação urbana em áreas contaminadas na cidade de São Paulo. Estudos Avançados, v. 28 n. 82, p. 129-137, 1 dez. 2014. Disponível em: http://www.revistas.usp.br/eav/article/view/88922/91787. Acesso em 27 de dez. de 2019.

IBGE - Instituto Brasileiro de Geografia e Estatística. Pesquisa Industrial Anual - Empresa. Disponível em: https://www.ibge.gov.br/estatisticas/economicas/industria/9042-pesquisa-industrialanual.html?=\&t=series-historicas. Acesso em 27 de dez. de 2019.

IRITANI, M. A.; ROSSINI-PENTEADO, D.; EZAKI, S.; ODA G. H. Perigo de contaminação da água subterrânea na região de Indaiatuba a Capivari, estado de São Paulo, Brasil. Revista do Instituto Geológico, São Paulo, v. 38, n.1, p. 1-16, 2017. http://dx.doi.org/10.5935/0100-929X.20170001.

LIMA, S. D.; OLIVEIRA, A. F.; GOLIN, R.; CAIXETA, D. S.; LIMA, Z. M.; MORAIS, E. B. Management of contaminated areas by gas stations in Cuiabá, Mato Grosso, Brazil. Rev. Ambient. Água, Taubaté, v. 12 n. 2, p. 299-315, Abr. 2017. http://dx.doi.org/10.4136/ambiagua.1872.

LOURENÇO, R. W.; LANDIM, P. M. B. Mapeamento de áreas de risco à saúde pública por meio de métodos geoestatísticos. Cadernos de Saúde Pública, v. 21, p. 150-160, 2005.

http://dx.doi.org/10.1590/S0102-311X2005000100017.

LOURENÇO, R. W.; SILVA, D. C. C.; MARTINS, A. C. G.; SALES, J. C. A.; ROVEDA, S. R. M. M.; ROVEDA, J. A. F. Use of fuzzy systems in the elaboration of an anthropic pressure indicator to evaluate the remaining forest fragments. Environmental Earth Sciences, v. 73, p. 1-8, 2015. https://doi.org/10.1007/s12665-015-4253-6.

LOURENÇO, R. W.; SILVA, D. C. C.; SALES, J. C. A.; MEDEIROS, G. A.; OTERO, R. A. P. Metodologia para seleção de áreas aptas à instalação de aterros sanitários consorciados utilizando SIG. Ciência e Natura, v. 37, p. 122-140, 2015.

http://dx.doi.org/10.5902/2179460X15973

LOURENÇO, R. W.; SILVA, D. C. C.; SALES, J. C. A. Development of a methodology for evaluation of the remaining forest fragments as a management tool and environmental planning. Ambiência, v. 10, p. 685-698, 2014. https://doi.org/10.5935/ambiencia.2014.03.03.

MAIOR, M. M.; CÂNDIDO, G. A. Avaliação das metodologias brasileiras de vulnerabilidade socioambiental como decorrência da problemática urbana no Brasil. Cadernos Metrópole, v. 16 n. 31, p. 241-264, 2014. http://dx.doi.org/10.1590/2236-9996.2014-3111.

MARION, F. A. Águas subterrâneas, atividades potencialmente contaminantes e o aporte do geoprocessamento na definição de conflitos. Geoambiente On-line, n. 17, p. 01-1, fev. 2012. https://doi.org/10.5216/revgeoamb.v0i17.26026.

MENEZES A. M. Estudo geofísico de vazamento de combustíveis em posto de abastecimento. Geociências, São Paulo, v. 30 n. 4, p. 601-609, 2011. Disponível em: 
http://www.ppegeo.igc.usp.br/index.php/GEOSP/article/view/7171/6616. Acesso em 17 de jan. de 2020

MORAES, S. L.; ECHEVENGUÁ TEIXEIRA, C.; MAXIMIANO, A. M. S. (Org.) Gerenciamento de Áreas Contaminadas: Guia de Elaboração de Planos de Intervenção. 1. ed. rev. São Paulo: IPT e BNDS, 2013. p. 13-27.

NERY, L. M.; CAMPOS, M. V. C.; SOUZA, M.; OLIVEIRA, R. A.; SILVA, D. C. C.; SIMONETTI, V. C. Estudo da capacidade de uso da terra na Bacia Hidrográfica do Rio Pirajibú-Mirim. In: Editora Poison (Org.). Meio Ambiente, sustentabilidade e tecnologia. Belo Horizonte, MG: Poisson, 2019. v. 2, p. 52-62. http://dx.doi.org/10.36229/978-85-7042-203-3.CAP.07

OLIVEIRA, P. D.; AYRES, F. M.; PEIXOTO FILHO, G. E. C.; MARTINS, I. P.; MACHADO, N. M. Geoprocessamento como ferramenta no licenciamento ambiental de postos de combustíveis.

Revista Sociedade \& Natureza, Uberlândia, v. 20, n. 1, p. 87-99, jun. 2008.

http://dx.doi.org/10.1590/S1982-45132008000100006

OLIVEIRA, R. A.; SILVA, D. C. C.; SIMONETTI, V. C.; STROKA, E. A. B.; SABONARO, D. Z. Proposição de Corredor Ecológico entre duas Unidades de Conservação na Região Metropolitana de Sorocaba. Revista do Departamento de Geografia, v. 32, p. 61-71, 2016.

https://doi.org/10.11606/rdg.v32i0.116467.

PESSOA, M. C. P. Y.; GOMES, M. A. F.; NEVES, M. C.; CERDEIRA, A. L.; SOUZA, M. D. Identificação de áreas de exposição ao risco de contaminação de águas subterrâneas pelos herbicidas atrazina, diuron e tebutiuron. Pesticidas: revista de ecotoxicologia e meio ambiente, v.13, 2003.http://dx.doi.org/10.5380/pes.v13i0.3171

SANTOS, A. S.; GARCIA VELASCO, F.; MARTÍNEZ LUZARDO, F. H.; ANDRADE, S. F. R.; NIETO GONZÁLEZ, L. Avaliação do risco toxicológico através da modelagem dinâmica da exposição aos compostos BTEX. Ambiência, Guarapuava - Paraná, v. 14 n. 1, p. 151 173, jan/abr. 2018. Disponível em: https://revistas.unicentro.br/index.php/ambiencia/article/view/4693. Acesso em 18 de jan. de 2020.

SÃO PAULO (Estado). Decreto Estadual no 59.263, de 5 de junho de 2013. Regulamenta a Lei no 13.577, de 8 de julho de 2009, que dispõe sobre diretrizes e procedimentos para a proteção da qualidade do solo e gerenciamento de áreas contaminadas, e dá providências correlatas. Diário Oficial do Estado, São Paulo, 6 jun. 2013.

SÃO PAULO (Estado). Lei no 13.577, de 8 de julho de 2009. Dispõe sobre diretrizes e procedimentos para a proteção da qualidade do solo e gerenciamento de áreas contaminadas, e dá outras providências correlatas. Diário Oficial do Estado, São Paulo, 8 jul. 2009.

SILVA, P. K. O. S.; MESQUITA, M. V. Avaliação do processo de remediação em área contaminada por hidrocarboneto. Revista Engenharia e Tecnologia Aplicada, v. 2 n. 1, p. 9-14, 2018. http://dx.doi.org/10.33947/2595-6264-v2n1-3497

SILVERMAN, B. W. Density Estimation for Statistics and Data Analysis. Nova York: Chapman and Hall,1986.

SIMONETTI, V. C.; SILVA, D. C. C.; OLIVEIRA, R. A.; SABONARO, D. Z.; ROSA, A. H. Análise da suscetibilidade do solo a processos erosivos do Parque Natural Municipal Corredores de Biodiversidade (PNMCBIO) de Sorocaba (SP). Raega-O Espaço Geográfico em Análise, v. 44, p. 169-180, 2018. http://dx.doi.org/10.5380/raega.v44i0.48838. 
SIMONETTI, V. C.; SABONARO, D. Z.; LOURENÇO, R. W.; ROSA. A.H.; SILVA, D. C. C. Análise da Variabilidade Espacial Horizontal e Vertical dos Atributos do Solo e sua Relevância para o Parque Natural Chico Mendes, SP. Revista Brasileira de Geografia Física, v. 12, n. 7, 2019.

SOROCABA. Lei $\mathbf{n} \mathbf{0}$ 11.022, de 16 de dezembro de 2014. Dispõe sobre a revisão do plano diretor de desenvolvimento físico territorial do município de Sorocaba e dá outras providências. Disponível em: https://leismunicipais.com.br/a2/plano-diretor-sorocaba-sp. Acesso em 17 de jan. de 2020

VALLADARES, G. S.; CAMARGO, O. A.; CARVALHO, J. R. P.; SILVA, A. M. C. Assessment of heavy metals in soils of a vineyard region with the use of principal component analysis. Sci. agric. (Piracicaba, Braz.), Piracicaba, v. 66 n. 3, p. 361-367, jun. 2009.http://dx.doi.org/10.1590/S010390162009000300011

WEBER, A. A.; WOLLMANN, C. A. Mapeamento dos incêndios residências na área urbana de Santa Maria, RS, Brasil utilizando o estimador de densidade Kernel. Investigaciones

Geográficas, n. 51, p. 49-60, 2016. http://dx.doi.org/\%2010.5354/0719-5370.2016.41748 